\title{
Development of Bus Driving Cycle for Debrecen on the Basis of Real-traffic Data
}

\author{
Attila Vámosi ${ }^{1 *}$, Levente Czégé², Imre Kocsis ${ }^{1}$ \\ 1 Department of Basic Technical Studies, Faculty of Engineering, University of Debrecen, Ótemető u. 2-4., 4028 Debrecen, \\ Hungary \\ 2 Department of Mechanical Engineering, Faculty of Engineering, University of Debrecen, Ótemető u. 2-4., 4028 Debrecen, \\ Hungary \\ *Corresponding author, e-mail: vamosi.attila@eng.unideb.hu
}

Received: 08 April 2020, Accepted: 20 April 2020, Published online: 28 January 2022

\begin{abstract}
In the literature it has been proven several times, that the common driving cycles are not accurate enough to estimate the fuel and energy consumption data or emission data for vehicles, especially for public transport vehicles, such as buses. One can find driving cycles for buses, but the special driving environment in Debrecen, Hungary cannot be accurately represented by them. As a part of a project focusing on the determination of fuel and energy consumption of vehicles by dynamic simulation, a study has been carried out for determining driving cycles, which are representative for Debrecen. In this paper the development of a driving cycle for city buses in Debrecen is presented. Typical bus routes were selected in the town for the study, the vehicles were instrumented with an appropriate data collecting system. These onboard units were used to collect data such as travelled distance, speed and acceleration on several vehicles in the real-world traffic. We used special purpose software to pre-process and filter the collected data. After pre-processing a statistical evaluation of the data was carried out. Using a version of the widely spread micro-trip method of driving cycle development, a Bus Driving Cycle has been constructed for Debrecen.
\end{abstract}

Keywords

driving cycle, urban bus route, real-traffic data

\section{Introduction}

In the literature one can find several different methods for driving cycle development. Most of these methods are based on statistical procedures applied on real-traffic data. Depending on the statistical method, on the considered characteristic parameters and on some other factors, different driving cycles can be developed for the same route (Huertas et al., 2019). The question is which procedure gives the optimal result regarding the representativeness of the driving cycle. Furthermore, even the indicators used to check the representativeness can be of different types. It can be stated that the development procedure of the optimal driving cycle depends, among others, on the purpose of the driving cycle, and on the quantity and quality of the data available. The goal of this paper is to develop a representative driving cycle for city buses in Debrecen. To find the most representative one, several driving cycles were prepared using different clustering parameters and different strategies of micro-trip selection and were compared on the basis of different characterizing parameters.

The driving cycles are important for emission reduction (Török and Zöldy, 2005; 2010). There are many papers dealing with the development of driving cycles for certain types of vehicles, e.g. for buses. The motivation behind most of these studies includes more accurate estimation of the fuel and energy consumption, as well as emission data of vehicles. It has been proven, that these values are regularly higher in the real world than those determined by the manufacturers based on the legislative driving cycles. To construct a driving cycle which properly describes the real driving patterns and reproduces the real fuel consumption and emission (Huertas et al., 2019) compares 3 methods on the basis of bus-fleet data obtained in 4 regions. Yuhui et al.'s work (2019) presents a method for driving cycle development with the same motivation behind it. 
The presented method is applied for public urban buses in Fuzhou city, China based on real-world driving data.

Due to the increasing number of hybrid and electric buses there is an urgent need for better understanding their driving characteristics. In Shen et al.'s work (2018) the driving cycle for an intra-city hybrid electric bus is developed with the aim of energy economy and emission performance testing, as well as control strategy optimization. Because of the special properties of electric vehicles their driving pattern is different from that of internal combustion engine driven vehicles. To prove this and help optimize the performances of the electric buses Tong (2019) presents a driving cycle for a particular bus route with supercapacitor buses deployed in Hong Kong.

Driving cycles are generally developed on the basis of two types of methods. In the first method, acceleration, idle speed, deceleration, and driving modes are combined to constitute a typical driving cycle, while in the second method, the driving cycle is derived from a large quantity of real-world statistical data (Chen et al., 2019). Extensive duty-cycle statistical analyses can be performed to examine and characterize common vehicle dynamics trends and relationships based on in-use field data.

The purposes of assessment criteria used for representative cycle synthesis are: extraction of driving characteristics; construction of candidate driving cycles; and determination of the statistical representativeness of the candidate driving cycles and the selection of the "best" cycle (Tong and Hung, 2010).

A driving condition cluster analysis methodology is proposed to establish the relationship between vehicle fuel consumption and driving condition type in Xie et al.'s work (2017).

In Brady and O'Mahony's work (2016) a stochastic and statistical methodology is used to develop and assess the representativeness of the driving cycle against a separate set of real-world data. For understanding the characteristics of driving cycles in depth the concepts of Distribution of speed interval, Distribution of acceleration interval, and the Speed acceleration frequency distribution are used in Gong et al.'s work (2018).

Regarding the cycle construction method, a random selection approach is adopted in Tong et al.'s work (2011). 10 acceptable cycles were generated for each vehicle type for the selection of the most representative driving cycle. In Kamble et al.'s work (2009) the data analysis is carried out in two parts as: analysis of base data and the analysis of micro-trips. The analysis of base data involves the development of the normalized speed-acceleration frequency matrix from which several parameters representing travel characteristics are computed.

\section{Basic data of the analysis}

Debrecen is a regional center with approximately 200,000 inhabitants, its area is $462 \mathrm{~km}^{2}$. It is located in a flat area without steep slopes. The relatively dense local network of public transport in Debrecen is based on bus, trolley bus and tram lines. A typical bus line is a combination of inner sections in the city center and outer sections in the suburbs. The average distance between two stops is approximately $200-300 \mathrm{~m}$ in the center and 400-500 m in the suburbs. The optimal selection of vehicles (size, type of drivetrain) is based on the analysis of the usage of vehicles in the real traffic, which can be described e.g. with driving cycles characteristic to the given settlement.

In the literature we can find many methods for data collection, like the chase car method, the on-board measurement method, and the hybrid method which is the combination of first two (Galgamuwa et al., 2015). In this study we used on-board diagnostic (OBD) tool to collect more than 50 trip activity information. The data acquisition system was installed on vehicles of the local public transport company. Our key data, collected second-by-second, included time, speed, acceleration, and traveled distance. Some of the characteristic parameters in the development process were used directly as obtained from the measurements, some were used after manipulations.

\section{Data processing and driving cycle construction \\ 3.1 Data filtering and micro-trip description}

There are several methods used in the literature to construct the cycle such as micro-trip cycle construction, trip segment-based cycle construction, cycle construction based on pattern classification, and modal cycle construction (Dai et al., 2008). In this study, the analysis of the travel data was performed by data processing based on the micro-trip method. The micro-trip is a trip between two stops caused by red traffic light signals, bus-stops for passengers getting on and off the bus, or other traffic situations. Such a section of travel includes acceleration, cruise, deceleration and idling parts. First, a filtration program was developed to eliminate the inaccurate data, and then, in the pre-processing step, we divided the original profiles into micro-trips using another program. 


\subsection{Determination of characterizing parameters}

For micro-trip clustering we have to extract driving features first. Many driving features can be defined for driving data. In this study, we used these common driving features:

- Average speed ( $v_{\text {total }}$ in $\left.\mathrm{km} / \mathrm{h}\right)$ : Average value of speed during a driving segment

- Average acceleration ( $a$ in $\mathrm{m} / \mathrm{s}^{2}$ ): Average value of positive accelerations

- Idle time ( $t_{\text {idle }}$ in percentage): the quotient of the idle time and the total time.

These parameters were chosen because they have the greatest effects on emissions (Fotouhi and Montazeri-Gh, 2013).

\subsection{The clustering procedure}

In this paper, clustering method is used for micro-trips partitioning. Clustering is the process of partitioning a given set of $n$ points into a number of groups, based on some similarity metric. We utilized the most commonly used unsupervised machine learning algorithm. The $k$-means clustering algorithm attempts to solve the clustering problem by optimizing a given metric (Fotouhi and Montazeri-Gh, 2013).

Before we do the actual clustering, we need to identify the optimal number of clusters for the dataset. Popular ways of determining the number of clusters are the Elbow Method, the Silhouette Method, and the Gap Static Method. Elbow and Silhouette methods are direct methods while Gap method is a statistics method (Yuan and Yang, 2019).

\subsection{Method of driving cycle construction}

After clustering the micro-trips and determining the proportion belonging to the clusters in the full dataset, for the construction of the driving cycle we need to select micro-trips from each cluster according to the specified proportions.
We used the following three methods:

1. the micro-trip closest to the cluster centers was selected from each cluster and was weighted with the specified proportions

2. micro-trips were randomly selected from each cluster, where the number of the selected micro-trips was determined on the basis of the specified proportions

3. given number of micro-trips were selected from each cluster which were closest to the center, where the number of the selected (different) micro-trips was determined on the basis of the specified proportions.

\section{Results}

\subsection{Determination of the optimum number of clusters}

First of all, we determined the optimum number of clusters in both modes. In the first mode the "Average speed" and the "Idle time percentage" were used as features for the clustering. As Fig. 1 shows, all of the three methods justified that the optimum number of clusters was two.

In the second mode the "Average speed" and the "Average acceleration" were used as featured for the clustering. In this case the optimum number of clusters was three, as shown in Fig. 2.

\subsection{Clustering}

In the first mode the micro-trips are clustered into two groups using the $k$-means clustering method. Each microtrip is represented as a point in the 2-dimensional feature space. In the scatter plot of the micro-trips in the feature space the different clusters are displayed in different colors in Fig. 3. The centers of the clusters are marked with black points.

Proportions belonging to the clusters in the total sample:

- proportion of Cluster 1 is 0.583

- proportion of Cluster 2 is 0.417 .

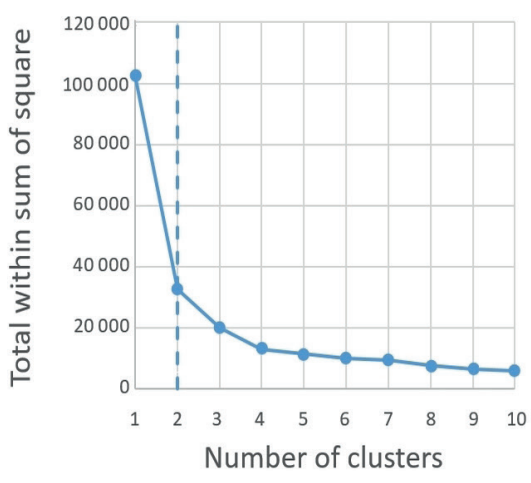

(a)

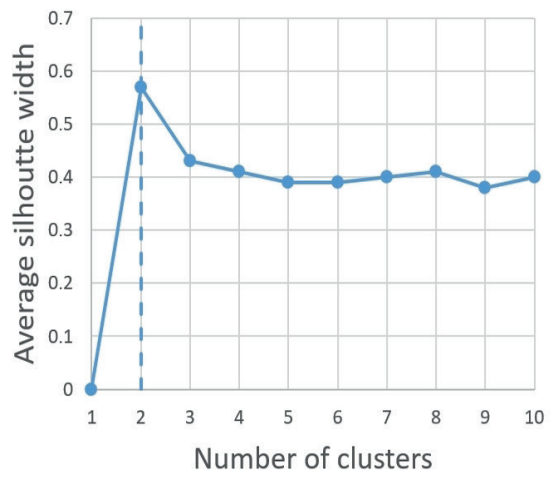

(b)

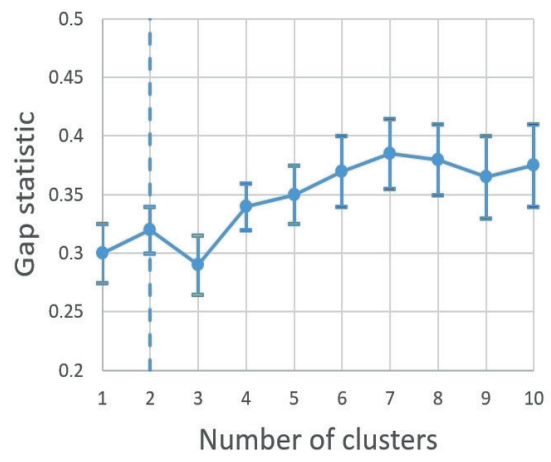

(c)

Fig. 1 Optimum number of clusters in the first mode (a) Elbow Method, (b) Silhoutte Method, (c) Gap Statistic Method 


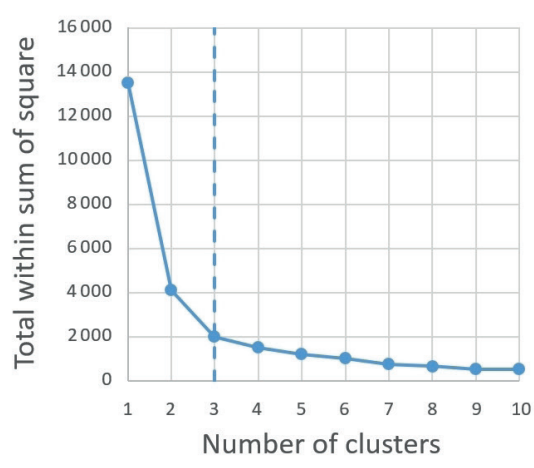

(a)

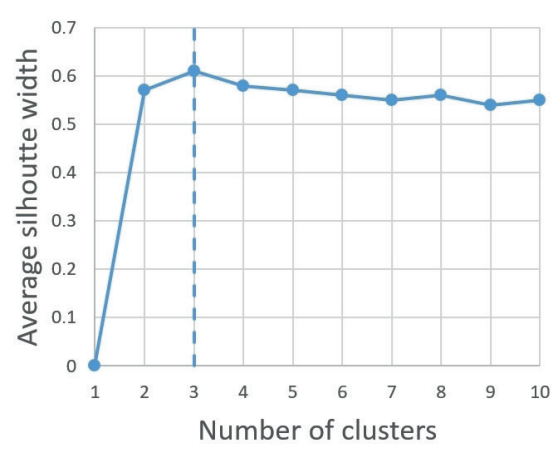

(b)

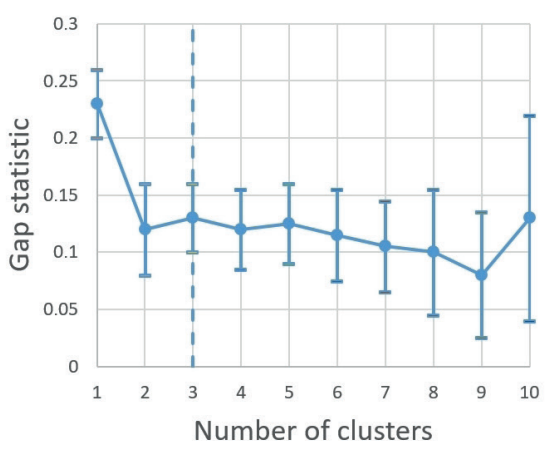

(c)

Fig. 2 Optimum number of clusters in the second mode (a) Elbow Method, (b) Silhoutte Method, (c) Gap Statistic Method

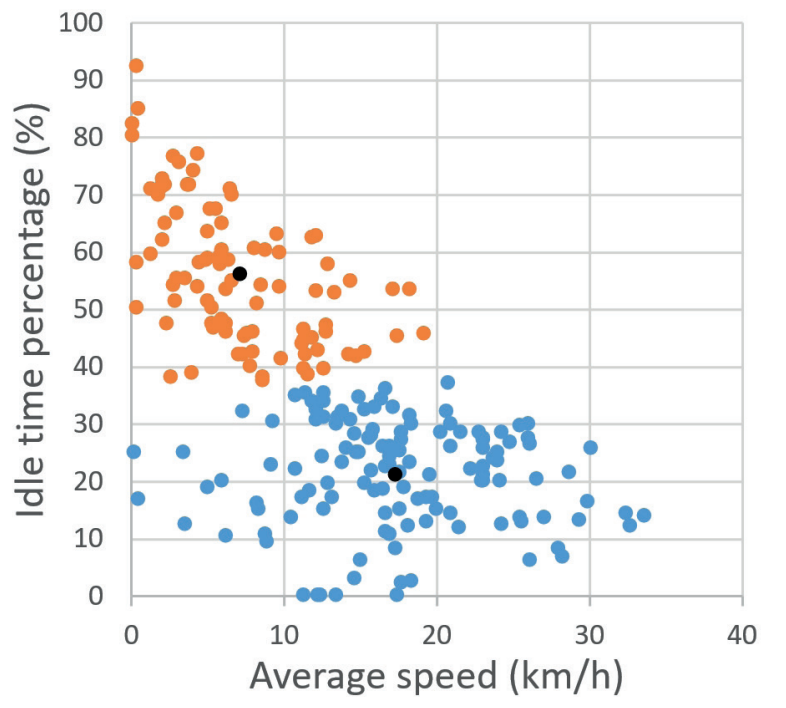

Fig. 3 Clustering result in the first mode

Thus, 6 micro-trips from Cluster 1 and 4 micro-trips from Cluster 2 are selected in the drive cycle construction (the true ratios are 0.6 and 0.4 , respectively).

In the second mode the micro-trips are clustered into three groups. The result and the centers of each cluster marked with a black point presented in Fig. 4.

Proportions belonging to the clusters in the total sample:

- proportion of Cluster 1 is 0.435

- proportion of Cluster 2 is 0.372

- proportion of Cluster 3 is 0.193 .

Thus, 4 micro-trips from Cluster 1 and Cluster 2, and 2 micro-trips from Cluster 3 are selected for the drive cycle construction (the true ratios are $0.4,0.4$, and 0.2 , respectively).

\subsection{Selection of micro-trips}

After clustering we constructed 6 different driving cycles depending on the two modes and three selection methods:

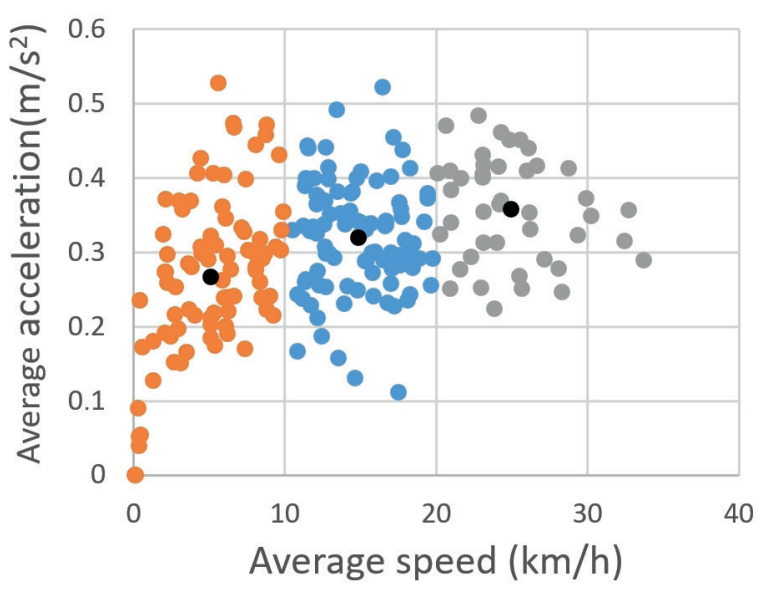

Fig. 4 Clustering result in the second mode

- DC11: the micro-trips closest to the centers of the two clusters were selected and used 6-times and 4-times;

- DC12: 6 micro-trips from Cluster 1 and 4 microtrips from Cluster 2 were selected randomly;

- DC13: 6 and 4 different micro-trips closest to the centers were selected from Clusters 1 and 2;

- DC21: the micro-trips closest to the centers of the three clusters were selected and used 4-times, 4-times and 2-times, respectively;

- DC22: 4, 2, and 2 micro-trips were randomly selected from Cluster 1, Cluster 2, and Cluster 3, respectively;

- DC23: 4, 2 and 2 different micro-trips closest to the centers were selected from Clusters 1, 2, and 3, respectively.

\subsection{Comparison based on characteristic parameters}

For the comparison we used the following driving cycle characteristic parameters:

- Average speed $\left(v_{\text {total }}\right.$ in $\left.\mathrm{km} / \mathrm{h}\right)$ : Average value of the speed during a driving segment;

- Average cruising speed $\left(v_{\text {cruise }}\right.$ in $\left.\mathrm{km} / \mathrm{h}\right)$ : Average value of the non-zero speeds; 
- Average acceleration ( $a$ in $\left.\mathrm{m} / \mathrm{s}^{2}\right)$ : Average value of the positive accelerations;

- Average deceleration $\left(d\right.$ in $\left.\mathrm{m} / \mathrm{s}^{2}\right)$ : Average value of the negative accelerations;

- Root mean square acceleration $\left(a_{\mathrm{RMS}}\right.$ in $\left.\mathrm{m} / \mathrm{s}^{2}\right)$ : root mean square of the positive and negative accelerations, calculated as

$$
a_{\mathrm{RMS}}=\sqrt{\sum_{i=1}^{n}\left(\frac{x_{i}-x_{i, a v g}}{x_{i, a v g}}\right)^{2}} ;
$$

- Idle time percentage ( $t_{\text {idle }}$ in \%): the quotient of the idle time and the total time in percentage.

In order to select the most representative driving cycle, the Root Mean Square (RMS) error was used. The RMS analysis aims to find the driving cycle with the lowest value of the overall RMS error comparing the statistical parameters of the sample and the average statistical parameters of the total dataset. As Table 1 shows, the drive cycle DC23 has the lowest RMS value, so this drive cycle represents the full dataset best.

\subsection{Comparison based on SAPD}

The Speed Acceleration Probability Distribution (SAPD) is an alternative tool to describe driving patterns (Huertas et al., 2019). It classifies the average speed and average acceleration of the vehicles into bins of speed-acceleration. Therefore, the similarity between the SAPD of the driving cycles and the SAPD of the full dataset is an indicator of representativeness of the driving cycle. The Quality of Fit (QoF), defined as

$\mathrm{QoF}=\sum_{i=1}^{n} \sum_{j=1}^{m}\left(P_{i j}-P_{i j}^{*}\right)^{2}$,

was used to evaluate the degree of similitude between SAPDs. The value closest to 0 indicates the best accuracy. The last row of Table 1 shows that the drive cycle DC23 has the lowest QoF value, that is, DC23 was proven to be the best again.

Fig. 5 (a) shows the SAPD of the full dataset, while Fig. 5 (b) shows the SAPD of the final driving cycle obtained with the three driving cycle construction methods. The visual inspection confirms the similarity of the two SAPDs.

Table 1 Driving cycle characteristic parameters

\begin{tabular}{|c|c|c|c|c|c|c|c|}
\hline Parameter & Total dataset & DC11 & $\mathrm{DC} 12$ & DC13 & DC21 & DC22 & DC23 \\
\hline Avg speed $(\mathrm{km} / \mathrm{h})$ & 13.197 & 13.243 & 13.948 & 13.072 & 12.955 & 16.095 & 13.025 \\
\hline Avg cruise speed $(\mathrm{km} / \mathrm{h})$ & 19.267 & 19.053 & 19.800 & 19.056 & 21.570 & 21.696 & 19.197 \\
\hline Avg acceleration $\left(\mathrm{m} / \mathrm{s}^{2}\right)$ & 0.308 & 0.266 & 0.320 & 0.278 & 0.355 & 0.346 & 0.295 \\
\hline Avg deceleration $\left(\mathrm{m} / \mathrm{s}^{2}\right)$ & -0.316 & -0.266 & -0.331 & -0.276 & -0.383 & -0.352 & -0.314 \\
\hline RMS acceleration $\left(\mathrm{m} / \mathrm{s}^{2}\right)$ & 0.612 & 0.562 & 0.632 & 0.585 & 0.663 & 0.653 & 0.571 \\
\hline Idle time percentage $(\%)$ & 35.622 & 34.732 & 33.970 & 35.015 & 45.457 & 28.700 & 36.142 \\
\hline RMS of full parameters & & 0.2268 & 0.1047 & 0.1677 & 0.4087 & 0.3664 & 0.0823 \\
\hline Quality of Fit value & & 0.0567 & 0.0425 & 0.0328 & 0.0354 & 0.0790 & 0.0278 \\
\hline
\end{tabular}

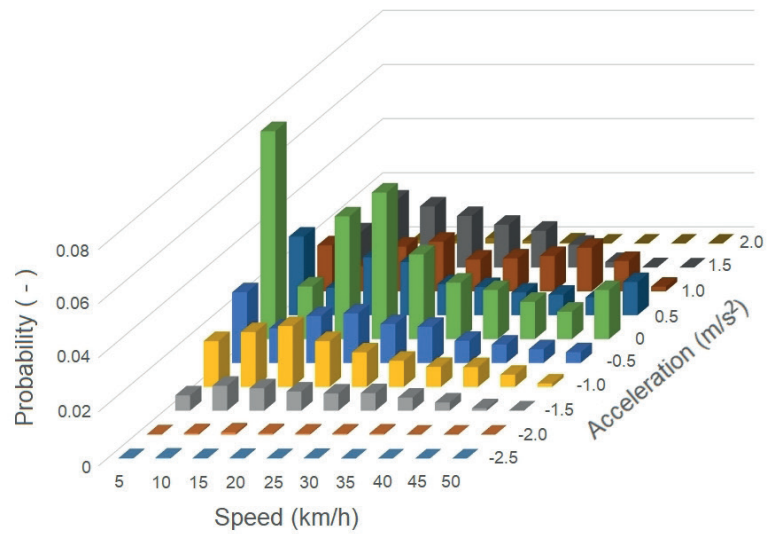

(a)

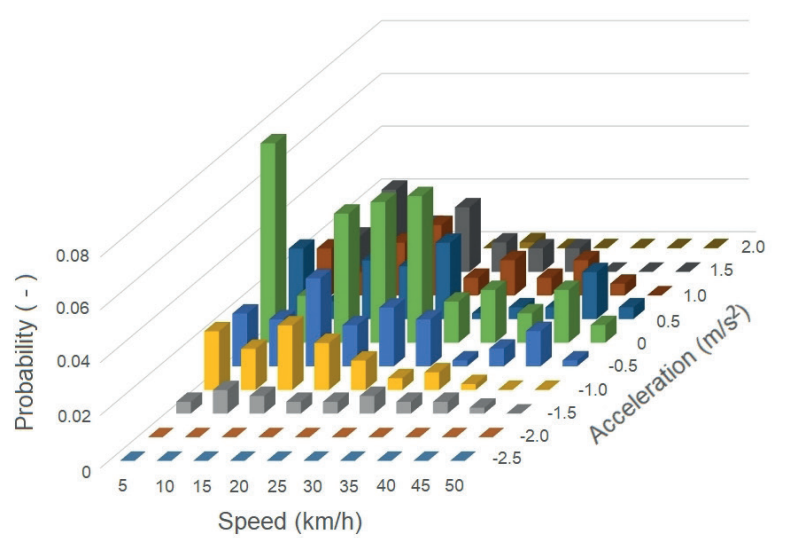

(b)

Fig. 5 (a) SAPD of the full dataset (b) SAPD of the final driving cycle 


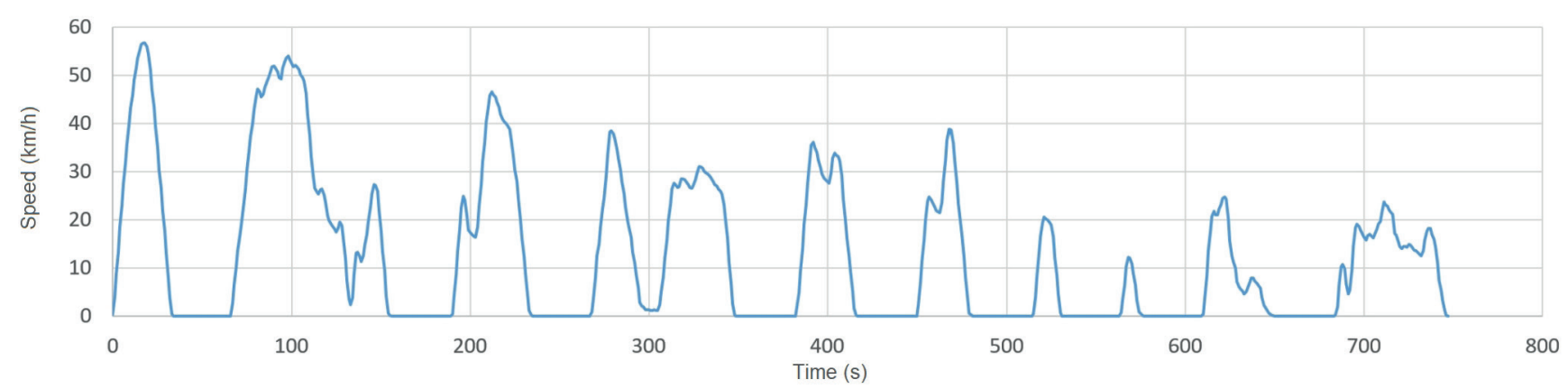

Fig. 6 Bus Driving Cycle for Debrecen

The Bus Driving Cycle constructed for Debrecen, which can be seen in Fig. 6, properly represents the original dataset. The total time of the cycle is $747 \mathrm{~s}$, the further parameters of the driving cycle are collected in Table 2.

\section{Conclusions}

In relation to a project focusing on determination of fuel and energy consumption by dynamic simulation of vehicles, there is a need for driving cycles specified for certain types of vehicles, regions, and applications. As these driving cycles aim to represent the characteristic of the load in the simulation, they have to be accurate enough to enable us to draw right conclusions. Based on this motivation, in this paper a driving cycle development procedure for the bus traffic in Debrecen is presented. Several versions of the driving cycles were constructed and compared, from which the most representative one was selected. The final representative Bus Driving Cycle for Debrecen will be used for further researches related to the evaluation and improvement of fuel economy of existing vehicles, as well as implementation of vehicles with alternative power source. In the next step of the research we are building a dynamic model of the vehicle. Based on the developed driving cycle, proper selection of the power source, the

\section{References}

Brady, J., O'Mahony, M. (2016) "Development of a driving cycle to evaluate the energy economy of electric vehicles in urban areas", Applied Energy, 177, pp. 165-178. https://doi.org/10.1016/j.apenergy.2016.05.094

Chen, Z., Zhang, Q., Lu, J., Bi, J. (2019) "Optimization-based method to develop practical driving cycle for application in electric vehicle power management: A case study in Shenyang, China", Energy, 186, Article number: 115766.

https://doi.org/10.1016/j.energy.2019.07.096

Dai, Z., Niemeier, D., Eisinger, D. (2008) "Driving Cycles: A New Cyclebuilding Method that Better Represents Real-world Emissions", Department of Civil and Environmental Engineering, University of California, Davis, CA, USA, Task Order No.: 66. [online] Available at: https://www.academia.edu/26820568 [Accessed: 09 December 2019]
Table 2 Parameters of Bus Driving Cycle for Debrecen

\begin{tabular}{lc}
\hline Parameter & Value \\
\hline Total time (s) & 747 \\
Cruise time (s) & 450 \\
Idle time (s) & 297 \\
Idle time percentage $(\%)$ & 36.142 \\
Average speed $(\mathrm{km} / \mathrm{h})$ & 13.025 \\
Average cruise speed $(\mathrm{km} / \mathrm{h})$ & 19.197 \\
Maximum speed $(\mathrm{km} / \mathrm{h})$ & 56.76 \\
Average acceleration $\left(\mathrm{m} / \mathrm{s}^{2}\right)$ & 0.295 \\
Average deceleration $\left(\mathrm{m} / \mathrm{s}^{2}\right)$ & -0.314 \\
Root mean square acceleration $\left(\mathrm{m} / \mathrm{s}^{2}\right)$ & 0.571 \\
Maximum acceleration $\left(\mathrm{m} / \mathrm{s}^{2}\right)$ & 1.57 \\
Maximum deceleration $\left(\mathrm{m} / \mathrm{s}^{2}\right)$ & -1.62 \\
\hline
\end{tabular}

optimization of the powertrain and the energy consumption can be realized in the future.

\section{Acknowledgement}

The research was financed by the Thematic Excellence Programme of the Ministry for Innovation and Technology in Hungary (ED_18-1-2019-0028), within the framework of the (Automotive Industry) thematic programme of the University of Debrecen.

Fotouhi, A., Montazeri-Gh, M. (2013) "Tehran driving cycle development using the $k$-means clustering method", Scientia Iranica: Transactions A: Civil Engineering, 20(2), pp. 286-293. https://doi.org/10.1016/j.scient.2013.04.001

Galgamuwa, U., Perera, L., Bandara, S. (2015) "Developing a General Methodology for Driving Cycle Construction: Comparison of Various Established Driving Cycles in the World to Propose a General Approach", Journal of Transportation Technologies, 5(4), pp. 191-203. https://doi.org/10.4236/jtts.2015.54018

Gong, H., Zou, Y., Yang, Q., Fan, J., Sun, F., Goehlich, D. (2018) "Generation of a driving cycle for battery electric vehicles: A case study of Beijing", Energy, 150, pp. 901-912. https://doi.org/10.1016/j.energy.2018.02.092 
Huertas, J. I., Quirama, L. F., Giraldo, M. D., Díaz, J. (2019) "Comparison of driving cycles obtained by the Micro-trips, Markov-chains and MWD-CP methods", International Journal of Sustainable Energy Planning and Management, 22, pp. 109-120.

https://doi.org/10.5278/ijsepm.2554

Kamble, S. H., Mathew, T. V., Sharma, G. K. (2009) "Development of real-world driving cycle: Case study of Pune, India", Transportation Research Part D: Transport and Environment, 14(2), pp. 132-140. https://doi.org/10.1016/j.trd.2008.11.008

Shen, P., Zhao, Z., Li, J., Zhan, X (2018) "Development of a typical driving cycle for an intra-city hybrid electric bus with a fixed route", Transportation Research Part D: Transport and Environment, 59, pp. 346-360.

https://doi.org/10.1016/j.trd.2018.01.032

Tong, H. Y., Hung, W. T. (2010) "A Framework for Developing Driving Cycles with On-Road Driving Data", Transportation Reviews, 30(5), pp. 589-615. https://doi.org/10.1080/01441640903286134

Tong, H. Y., Tung, H. D., Hung, W. T., Nguyen, H. V. (2011) "Development of driving cycles for motorcycles and light-duty vehicles in Vietnam", Atmospheric Environment, 45(29), pp. 5191-5199. https://doi.org/10.1016/j.atmosenv.2011.06.023

Tong, H. Y. (2019) "Development of a driving cycle for a supercapacitor electric bus route in Hong Kong", Sustainable Cities and Society, 48, Article number: 101588.

https://doi.org/10.1016/j.scs.2019.101588
Török, Á., Zöldy, M. (2005) "A forgalomba belépő gépjármúvek többlet károsanyag kibocsátásának számítása a nemzetközi határértékek figyelembevételével" (Calculation of the excess emissions of extra vehicles in the traffic, taking into account international limit values), [pdf] Közlekedéstudományi Szemle, 55, pp. 336-339. Available at: http://real.mtak.hu/5030/1/1133180.pdf [Accessed: 09 December 2019] (in Hungarian)

Török, Á., Zöldy, M. (2010) "Energetic and Economical Investigation of Greenhouse Gas Emission of Hungarian Road Transport Sector", Pollack Periodica, 5(3), pp. 123-132 https://doi.org/10.1556/Pollack.5.2010.3.10

Xie, H., Tian, G., Chen, H., Wang, J., Huang, Y. (2017) "A distribution density-based methodology for driving data cluster analysis: a case study for an extended-range electric city bus", Pattern Recognition, 73, pp. 131-143.

https://doi.org/10.1016/j.patcog.2017.08.006

Yuan, C., Yang, H., (2019) "Research on K-Value Selection Method of K-Means Clustering Algorithm", J Multidisciplinary Scientific Journal, 2(2), pp. 226-235. https://doi.org/10.3390/j2020016

Yuhui, P., Yuan, Z., Huibao, Y. (2019) "Development of a representative driving cycle for urban buses based on the K-means cluster method", Cluster Computing, 22(Supplement 3), pp. 6871-6880. https://doi.org/10.1007/s10586-017-1673-y 